\title{
Clinical Experiences for Unvaccinated Nursing Students
}

$\mathrm{T}$

hroughout 2021, practicing nurses have managed to navigate a complex web of federal, state, and local guidance; procedures enacted by private institutions and businesses; and a constant onslaught of misinformation, all while weathering the COVID-19 pandemic. Nursing students must also manage these complexities, including the decision of whether to receive a COVID-19 vaccine. Because of a medical condition, a sincerely held religious belief, or personal hesitance, some nursing students remain unvaccinated. However, their unvaccinated status presents a challenge to their education, as many clinical sites require all healthcare providers, including students, to be vaccinated. As a result, these students may be unable to complete their clinical experiences onsite - a problem that is expected to intensify with the Biden administration's recent mandates. As nursing program faculty and administrators struggle with the question of whether to provide alternate clinical education for these students, the National Council of State Boards of Nursing (NCSBN) convened a number of prominent nursing and healthcare organizations to discuss the matter, and the policy brief below is the result of that discussion (Figure 1). Considering its timeliness, the Journal of Nursing Regulation wished to share the message with its readers.

\section{Policy Brief: Clinical Experiences for Unvaccinated Nursing Students Purpose}

To provide guidance to boards of nursing and nursing education programs that are receiving requests from students for alternate clinical experiences when the program's clinical sites require the COVID-19 vaccine.

\section{Context}

Currently, nursing programs are receiving requests from unvaccinated students to provide alternate experiences when the designated clinical facility mandates the COVID-19 vaccine. These requests range from using $100 \%$ simulation as a substitute for the clinical experience to the program finding other types of activities and case studies/scenarios.

Much of the fear and concern over receiving the vaccine is based on misinformation and lack of knowledge about the vaccine and its development (U.S. Department of Health and Human Services, 2021). According to one study, as of August 2021, 92\% of nursing faculty were vaccinated or planned to be vaccinated and $86 \%$ of currently enrolled students have been vaccinated (National Student Nurses Association, 2021). Thus, it is a small number of students who are vaccine-hesitant and affected by vaccine mandates. This policy addresses these students.
Clinical experiences are integral to nursing education. NCSBN's National Simulation Study (Hayden et al., 2014) demonstrated that up to $50 \%$ of clinical experience can be substituted with simulation. According to the American Association of Colleges

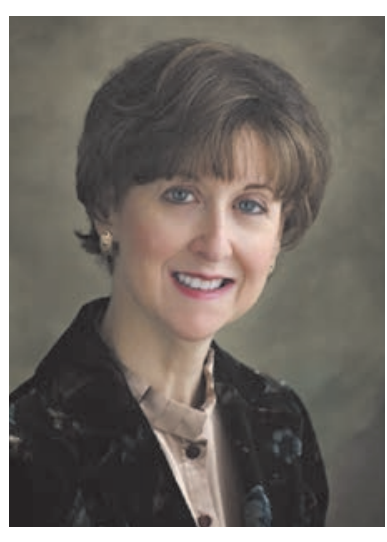
of Nursing (AACN) The Essentials: Core Competencies for Professional Nursing Education, "Simulation experiences represent an important component of clinical education.... However, care experiences with actual individuals or groups continue to be the most important component of clinical education. ... Simulation cannot substitute for all direct care practice experiences in any one sphere or for any one age group" (AACN, 2021, p. 21).

As of August 23, 2021, the Pfizer vaccine has received full Food and Drug Administration approval. The vaccine protects healthcare professionals and students as well as patients. In fact, millions of people in the United States have received COVID-19 vaccines. All three of the vaccines available in the United States have undergone the most rigorous safety monitoring in U.S. history (Centers for Disease Control and Prevention, 2021).

The COVID-19 vaccine's authorization is based on scientific evidence (Food and Drug Administration, 2021). Identifying, assessing, and integrating reliable evidence into one's practice has been and continues to be an expectation for the preparation of professional nurses (AACN, 2008, 2021). Unvaccinated individuals are at risk for contracting COVID-19, thereby increasing the chances for more variants to emerge and, more importantly, putting vulnerable individuals at risk, especially hospitalized patients, nursing home residents, healthcare professionals, and peers who may be immunocompromised (Plater, 2021).

\section{Recommendations}

- Students should be vaccinated when clinical facilities require it so that they can participate in the clinical experience and progress in their programs.

- Nursing education programs should reach out to students who are vaccine-hesitant and counsel the students about the benefit of the vaccine and the need for it as a student enrolled in a nursing program, and they should address myths and misleading information about the vaccine.

- Course descriptions should include that a clinical component is required.

- Nursing education programs are mandated by boards of nursing as well as accreditors to provide students with clinical experiences. They 


\section{FIGURE 1}

\section{Nursing Organizations Who Have Endorsed the Policy Brief}

National Council of State Boards of Nursing (NCSBN)

Accreditation Commission for Education in Nursing (ACEN)

American Association of Colleges of Nursing (AACN)

American Nurses Association (ANA)

American Organization for Nursing Leadership (AONL)

National League for Nursing (NLN)

NLN Commission for Nursing Education Accreditation (CNEA)

National Student Nurses' Association (NSNA)

Organization for Associate Degree Nursing (OADN)

are not obligated to provide substitute or alternate clinical experiences based on a student's request or vaccine preference.

- Just as the nursing education program and/or clinical facilities require other vaccines, the facilities have the option to mandate the COVID-19 vaccine.

- Boards of nursing have no obligation to waive their current rules/regulations about clinical experiences for unvaccinated students.

- Transparency is essential. Even if mandated by the academic institution, students can refuse the vaccine. Therefore, if the student refuses to be vaccinated and is not entitled to a reasonable accommodation under the disability laws* or is not entitled to a reasonable accommodation for a sincerely held religious belief, then the student (a) may be disenrolled from the institution/nursing program or (b) may not be able to fulfill the clinical requirements of the program, resulting in them not graduating.

- Accommodations made for students under disability laws or for a sincerely held religious belief should be decided on a case-by-case basis.

$$
\begin{array}{r}
\text { Maryann Alexander, PhD, RN, FAAN } \\
\text { Editor-in-Chief }
\end{array}
$$

Hayden, J. K., Smiley, R. A., Alexander, M., Kardong-Edren, S., \& Jeffries, P. R. (2014). The NCSBN National Simulation Study: A longitudinal, randomized, controlled study replacing clinical hours with simulation in prelicensure nursing education. Journal of Nursing Regulation, 5(2 Suppl.), S3-S40. https://doi.org/10.1016/S21558256(15)30062-4

National Student Nurses Association. (2021, August 16). Survey of vaccination status July 1 - August 15 th for nursing students, faculty and new graduates reveals unexpected results. Retrieved September 24, 2021, from https://www.nsna.org/uploads/2/2/4/5/22459246/national_ student_nurses_press_release_-_report_of_july_2021_survey_of vaccination_rates_-_final.pdf

Plater, R. (2021, August 10). Unvaccinated people are increasing the chances for more coronavirus variants-Here's how. Healthline. https://www.healthline.com/health-news/unvaccinated-people-areincreasing-the-chances-for-more-coronavirus-variants-heres-how

U.S. Department of Education Office for Civil Rights. (2011). Students with disabilities preparing for postsecondary education: Know your rights and responsibilities. https://www2.ed.gov/about/offices/list/ocr/ transition.html

U.S. Department of Health and Human Services. (2021). Addressing COVID-19 vaccine misconceptions. Retrieved September 24, 2021, from https://wecandothis.hhs.gov/outreach-tools/addressing-covid19-vaccine-misconceptions

Conflicts of Interest: None.

\section{References}

American Association of Colleges of Nursing. (2008). The essentials of baccalaureate education for professional nursing practice. https://www. aacnnursing.org/Portals/42/Publications/BaccEssentials08.pdf

American Association of Colleges of Nursing. (2021). The essentials: Core competencies for professional nursing education. https://www.aacnnursing. org/Portals/42/AcademicNursing/pdf/Essentials-2021.pdf

Centers for Disease Control and Prevention. (2021, September 20). Safety of COVID-19 vaccines. Retrieved September 24, 2021, from https://www.cdc.gov/coronavirus/2019-ncov/vaccines/safety/safetyof-vaccines.html

Food and Drug Administration. (2021). FDA approves first COVID-19 vaccine [News release]. https://www.fda.gov/news-events/pressannouncements/fda-approves-first-covid-19-vaccine

* In providing an academic adjustment to students with disabilities, postsecondary schools are not required to lower or substantially modify essential requirements (U.S. Department of Education, 2011).

4 Journal of Nursing Regulation 